\title{
An Experience of Pandemic Influenza A (H1N1) 2009 Virus Outbreak in 2017 at Tertiary Care Hospital, Chennai, Tamilnadu, India
}

\author{
N. Thilakavathi* and Shanthi B. Rosyvennila \\ Department of Microbiology, Govt. Stanley Medical College and Hospital, Chennai, \\ Tamil Nadu, India \\ *Corresponding author
}

Keywords

Influenza A (H1N1), ILI Category C, Oseltamivir, Diabetes mellitus Ante natal

Article Info

Accepted:

28 March 2018

Available Online:

10 April 2018

\section{A B S T R A C T}

Influenza A (H1N1) is a disease of major public health concern of high mortality. India has reported 27,236 lab confirmed cases with 981 deaths in 2009 pandemic, followed by outbreaks in 2015 and 2016. The most recent outbreak in 2017 reported around 1094 deaths. Hence this study was carried out in patients admitted with influenza-like illness (ILI Category C) to identify the risk factors associated with the disease. Retrospective study was conducted among patients admitted in Stanley Medical College with ILI (Cat C) between January 2017 and June 2017. Nasopharyngeal/throat swabs were collected and tested by RT-PCR. PCR was done for four influenza target genes. The demographic details, clinical features, results of RT-PCR for H1N1 and other investigations were analyzed retrospectively. Out of the 360 ILI Cat C subjects, 103 samples were positive for H1N1 by RT-PCR including 2 brought dead cases. There was a clustering of cases in the months of January-February (79\%). All H1N1 positives were from northern Tamilnadu with $83 \%$ of cases from Thiruvallur district. 55\% cases were between 21-60 years of age and $76 \%$ cases were females including $33 \%$ Ante Natal women. Patients most commonly presented with fever $(100 \%)$, myalgia $(76 \%)$, running nose $(62 \%)$ and shortness of breath $(38 \%)$. The comorbid conditions were diabetes mellitus (37\%), hypertension $(25 \%)$ and COPD (25\%), bronchial asthma and TB (10\%). Among the laboratory confirmed results $33 \%$ were antenatal women. All patients were isolated and treated with oseltamivir and necessary respiratory support. Timely diagnosis, early treatment and strict hospital infection control practices prevented adverse outcomes (nil mortality). This study showed that antenatal patients and diabetic individuals are at highest risk.

\section{Introduction}

Influenza A (H1N1) is a disease of major public health concern as it is associated with high mortality and morbidity. The pandemic strain influenza A (H1N1) has first appeared in Mexico and triggered the first pandemic in April 2009 (Centers for Disease Control and Prevention, 2009; Singhal et al., 2014). In
India the first outbreak of pandemic influenza A (H1N1) was reported in 2009 from Hyderabad (Pandemic, 2009). Many outbreaks of this strain have occurred in India from 2009 to till date. In 2009, India has reported 27,236 laboratory confirmed cases with 981 deaths (Gupta et al., 2011). In 2015 pandemic, influenza A (H1N1) virus epidemic become widespread with 29,978 confirmed cases and 
1793 deaths in India (Emergency Medical Relief, 2015).

In Tamilnadu 1786 confirmed cases and 265 deaths has occurred this year 2016 (January December). This disease shows bimodal distribution in India with a major peak in rainy season (July - August) and minor peak in winter and spring season (December February). The climate also differs enormously in various regions of India.

As the virus shows great antigenic variation due to antigenic shift, drift and genetic reassortment, the development of effective vaccine becomes difficult. Since the routine seasonal vaccination does not exist in India, identifying risk factors for adverse outcomes and targeting high risk groups for vaccination becomes of utmost importance. Hence the study was taken up to analyze the epidemiology, clinical profile and risk factors from patients with influenza like illness (ILI).

\section{Materials and Methods}

The study was a retrospective, record based analysis of patients admitted with clinical Category-C (http://www.mohfw.nic.in/Write ReadData/1892s/804456402Categoisation.pdf) of influenza like illness in Government Stanley Medical College and Hospital from January 2017to July 2017

Throat / Nasal swab sample of suspected patients were collected in viral transport medium maintaining cold chain were received and tested in the referral laboratory (MMC\&RGGGH Chennai). RNA was extracted by Q1amp viral RNA Mini Kit (Qiagen, Germany). RNA of each isolate was tested by separate primer/probe sets for InfA, Universal Swine (swFluA), Swine H1 (swH1) and RNaseP (Applied Biosystems, USA) as per the CDC real-time RT-PCR protocol (ABI
Step One Plus RT-PCR instrument - Applied Biosystems, USA) (http://www.who.int/csr/ resources/publications/swineflu/CDCRealtime RTPCR_SwineH1 Assay-2009_ 20090430. pdf). The epidemiological profiles of all pandemic influenza A (H1N1) 2009 virus cases were analyzed in terms of demographic characteristics, clinical presentation and outcome.

\section{Results and Discussion}

A total of 360 samples include 2 postmortem samples and category-C patients suspected to have pandemic Influenza A ( $\mathrm{H}_{1}$ N1) 2009 virus infection were tested in the period January 2017 to July 2017. The individuals' accessed treatment for ILI was from North Chennai \& Thiruvallur District. Out of 360 samples tested 103 (29\%) found to be positive. Most of the samples were from North Chennai with most of the positive cases (77 cases) from Thiruvallur district. Two patients died due to pandemic Influenzae A (H1N1) 2009, was brought dead and the respiratory secretions were confirmed by PCR. Both the deceased persons were aged 18and 30 years from Gummidipoondi Taluk of Thiruvallur District belongs to Gypsy group.4 samples were tested from Health care personnel (HCP) out of which one were confirmed positive.

Monthly distribution of pandemic Influenzae A (H1N1) 2009 positive cases from January 2017 to July 2017 is shown in graph 1 . As per the statistics there was clustering of cases occurs in the month of January and February after which the number of suspected cases and confirmed cases declines (Fig. 1).

The age and department wise distribution of the cases was shown in Figure 2 and 3. Out of 103 confirmed cases 57 were between 21-60 years of age, 26 were in the age group 0-5 years. 
Fig.1 Month wise distribution of suspected cases and positive results for pandemic Influenza A (H1N1) 2009 virus

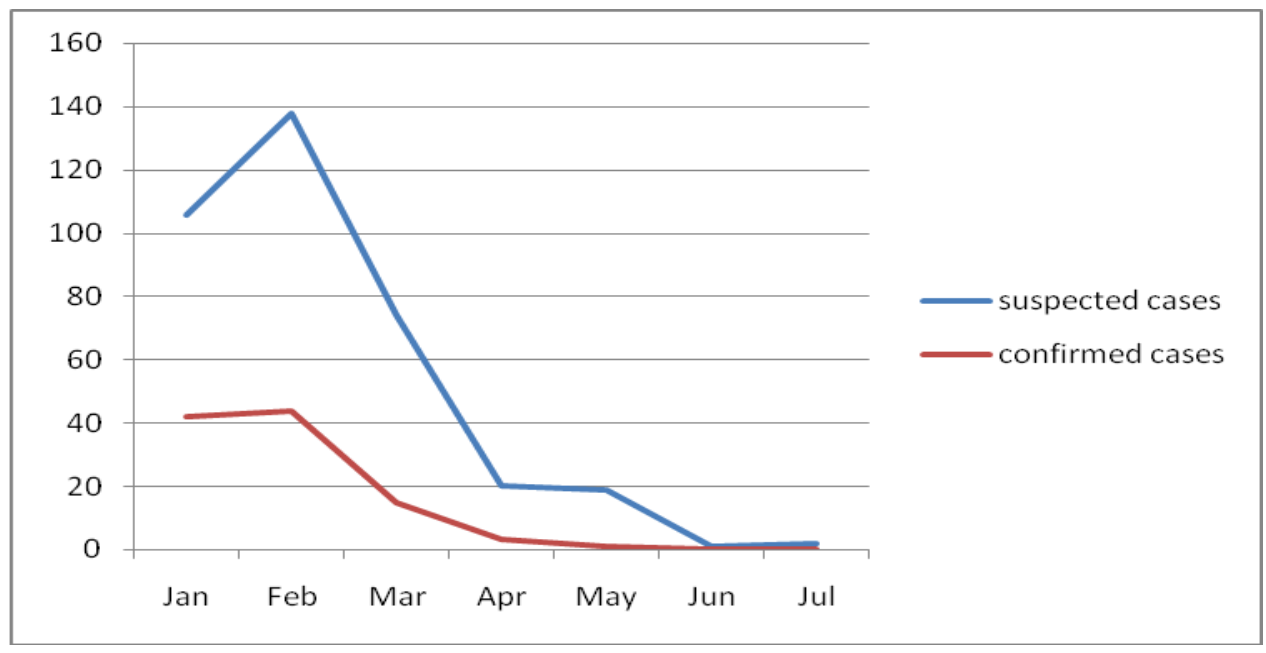

Fig.2 Department wise distribution of suspected and positive cases

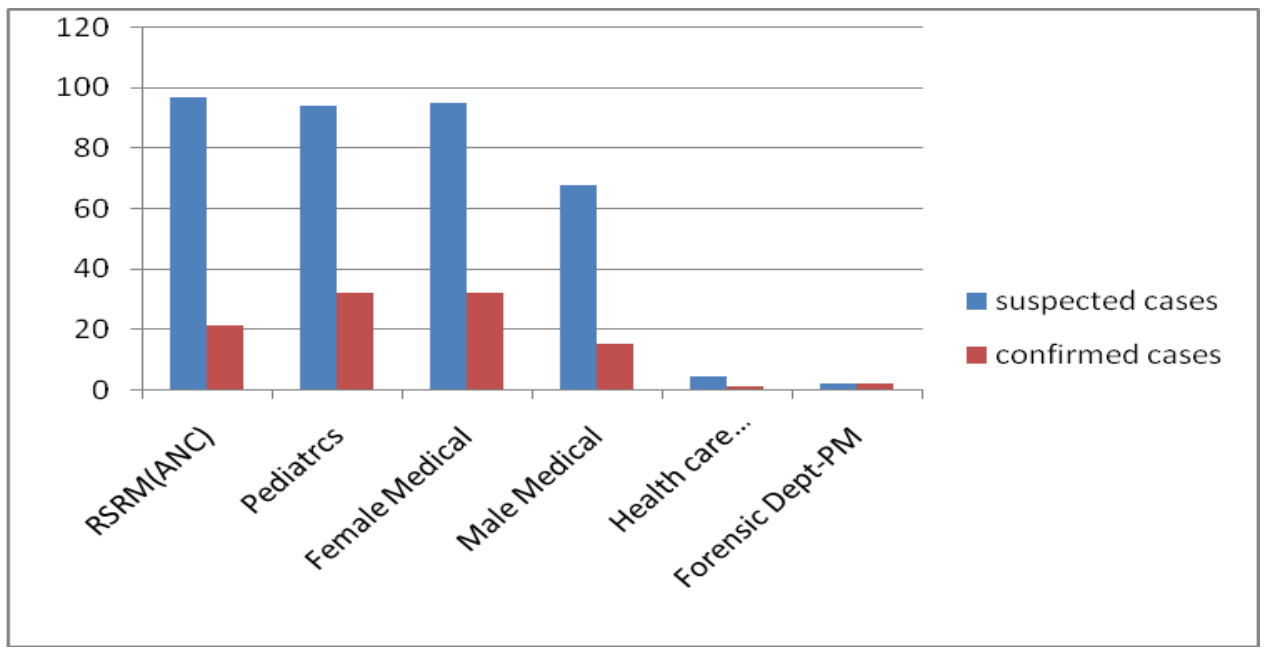

Fig.3 Age wise distribution of positive cases

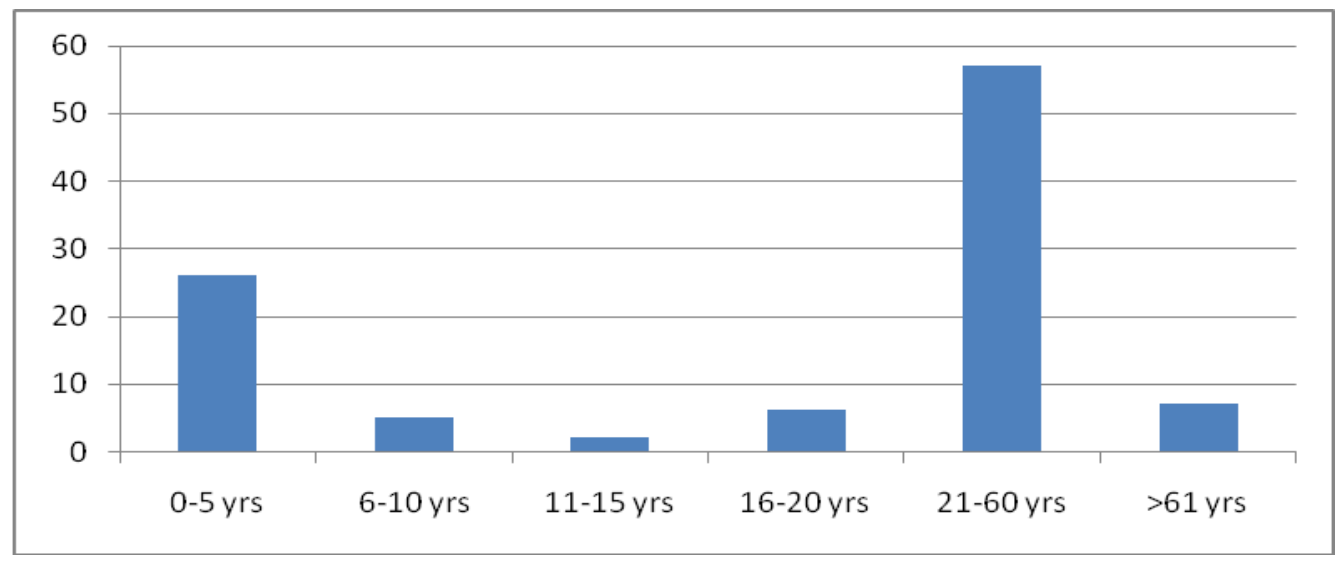


Fig.4 Co-morbidities among positive cases

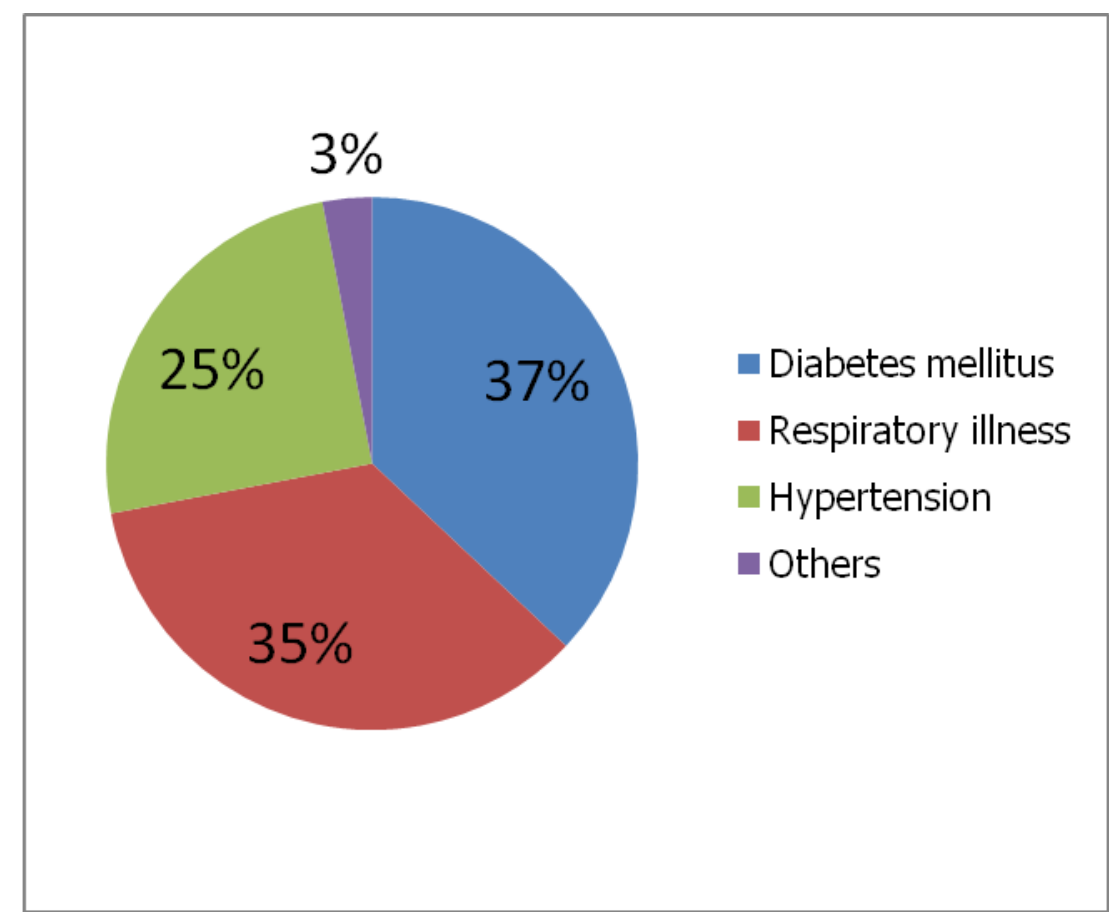

The pandemic Influenza A (H1N1) 2009 rate was higher in female Medical ward $32 \%$, pediatric department 31\%, antenatals obstetrics department (RSRM) 20\% and male medical ward $14 \%$.

Fever, myalgia, running nose, shortness of breath, cough, diarrhea and vomiting were the common symptoms. Apart from pregnancy the associated risk factors are Diabetes mellitus 37\%, Respiratory illness 35\%, Hypertension 25\% and others3\% (Liver and Kidney diseases)

In the present study clustering of cases occurs in the month of January and February with a decline subsequently. The relationship to the influenza virus with low temperature reported from the states of India (Singh et al., 2015; Jain et al., 2009; Koul et al., 2014; Chadha et al., 2015)

The case fatality rate (CFR) was less than $1.9 \%$ compared to other states of India and equal to previous studies from Tamilnadu
(Puvanalingam et al., 2011). The CFR was found to be 12.6 and $21 \%$ in 2012 and 2013 in Western Rajasthan (Chowell et al., 2011; Singh et al., 2012), $1.8 \%$ from south India (Puvanalingam et al., 2011) and $17.9 \%$ in hospitalized patients at Jaipur (Sharma et al., 2015).

In the present study, the mortality of females is nil positivity was higher in females $34 \%$ as reported earlier from Gujarat (64.2\%) (Gelotar et al., 2015) and Rajasthan (64.22\%) (Sharma et al., 2012). Positivity were predominantly seen 21-60 yrs age group in the present study as has been earlier reported from India and other countries (Singh et al., 2015; Singh et al., 2013; Taklikar and Nanaware, 2013; Pebody et al., 2009; Louie et al., 2009). People in this age group are mostly working and thus liable to get exposed to pandemic influenza A (H1N1) 2009 infection while those above 60 yrs may have had greater immunity due to previous exposure to similar viruses (Itolikar and Nadkar, 2015; Dawood et al., 2012). Children 
of under 5 years of age group are also affected to a greater extent, may be due to underdeveloped immune system.

In the present study the major co-morbid conditions associated were diabetes mellitus $37 \%$, respiratory disorders $35 \%$, hypertension $25 \%$ among the confirmed subjects (Fig. 4). Diabetes, heart and respiratory diseases along with anaemia, obesity and cancer were the common co-morbidities reported in Indian and Californian studies (Puvanalingam et al., 2011; Taklikar and Nanaware, 2013).

In conclusion, our study showed less mortality and morbidity due to pandemic influenza A (H1N1) 2009 virus infections, particularly in the children (under five years) and middle-aged population. The epidemic was more severe during January 2017 and February 2017. Pregnancy, diabetes, respiratory diseases, and hypertension were the common predisposing factors. Females and children were affected predominately than males. Vaccination of health care personnel's at risk prevented them from ILI. Regular surveillance, early diagnosis, isolation practices and timely initiation of Oseltamivir therapy and supportive treatment in suspected cases would be helpful to reduce mortality and morbidity.

\section{Acknowledgement}

Authors acknowledge the support of all members of the Molecular diagnostic laboratory (Swine flu), Institute of Microbiology, RGGH, Chennai, Tamilnadu, India.

\section{References}

CDC Protocol of Real Time RTPCR for Influenza A (H1N1) [Accessed on June 10, 2015].
Centers for Disease Control and Prevention (CDC). Update: Novel Influenza A (H1N1) Virus Infection: Mexico, MarchMay, 2009. MMWR Morb Mortal Wkly Rep. 2009; 58: 585-9.

Chadha MS, Potdar VA, Saha S, Koul PA, Broor S, Dar L, et al., Dynamics of influenza seasonality at sub-regional levels in India and implications for vaccination timing. PLoS One. 2015; 10: e0124122.

Chowell G, Echevarría-Zuno S, Viboud C, Simonsen L, Tamerius J, Miller MA, et al., Characterizing the epidemiology of the 2009 influenza A/H1N1 pandemic in Mexico. PLoS Med. 2011; 8: e1000436.

Dawood FS, Iuliano AD, Reed C, Meltzer MI, Shay DK, Cheng PY, et al., Estimated global mortality associated with the first 12 months of 2009 pandemic influenza A H1N1 virus circulation: a modelling study. Lancet Infect Dis. 2012; 12: 68795.

Emergency Medical Relief (EMR), Ministry of Health and Family Welfare, Government of India. [Accessed on May 11, 2015]. Available from: http://mohfw.nic.in/index3.php?lang=1\&1 evel $=0 \&$ deptid $=115$

Gelotar PS, Durani K, Gandha KM, Sanghavi MM. Epidemiological characteristics including seasonal trend of hospital based swine flu cases in Jamnagar region, Gujarat, India. J Res Med Dent Sci. 2015; 3: 39-42.

Guidelines on Categorization of Influenza A H1N1 Cases during Screening for Home Isolation, Testing Treatment, and Hospitalization.

Gupta SD, Lal V, Jain R, Gupta OP. Modeling of H1N1 outbreak in Rajasthan: methods and approaches. Indian J Community Med. 2011; 36: 368. 
Itolikar S, and Nadkar MY. H1N1 revisited after six years: then and now. J Assoc Physicians India. 2015; 63: 41-3.

Jain S, Kamimoto L, Bramley AM, Schmitz AM, Benoit SR, Louie J, et al., Hospitalized patients with 2009 H1N1 influenza in the United States, April-June 2009. N Engl J Med. 2009; 361: 193544.

Koul PA, Broor S, Saha S, Barnes J, Smith C, Shaw M, et al., Differences in influenza seasonality by latitude, Northern India. Emerg Infect Dis. 2014; 20: 1723 6.

Louie JK, Acosta M, Winter K, Jean C, Gavali S, Schechter R, et al., Factors associated with death or hospitalization due to pandemic 2009 influenza $\mathrm{A}(\mathrm{H} 1 \mathrm{~N} 1)$ infection in California. JAMA. 2009; 302: 1896-902.

Pandemic (H1N1) 2009 Briefing Note 23. WHO Recommendations for the PostPandemic Period. [Accessed on May 11, 2016]. Available from: http://www.who. int/csr/disease/swineflu/notes/briefing_20 100810/en/

Pebody RG, McLean E, Zhao H, Cleary P, Bracebridge S, Foster K, et al., Pandemic influenza A (H1N1) 2009 and mortality in the United Kingdom: Risk factors for death, April 2009 to March 2010. Euro Surveill. 2010; 15 pii: 19571.

Puvanalingam A, Rajendiran C, Sivasubramanian K, Ragunanthanan S, Suresh S, Gopalakrishnan S. Case series study of the clinical profile of H1N1 swine flu influenza. J Assoc Physicians India. 2011; 59: 14-6. 18.
Sharma CP, Keerti, Sharma S, Kumar A, Gupta MK. Demographic correlates of swine flu cases attending a tertiary care hospital in Rajasthan. Indian $\mathrm{J}$ PrevSoc Med.2012; 43: 224-8.

Sharma R, Agarwal S, Mehta S, Nawal CL, Bhandari S, Rathore M, et al., Profiling the mortality due to influenza A (H1N1) pdm09 at a tertiary care hospital in Jaipur during the current season - January \& February 2015. J Assoc Physicians India. 2015; 63: 36-9.

Singh M, Bhansali S, Hakim A, Sharma S. Epidemiological profile of $\mathrm{H} 1 \mathrm{~N} 1$ cases in Western Rajasthan from January 2012 to December 2012. Indian J Public Health Res Dev. 2015; 6: 118-22.

Singh M, Bhansali S, Hakim A, Sharma S. Epidemiological profile of $\mathrm{H} 1 \mathrm{~N} 1$ cases in Western Rajasthan from January 2012 to December 2012. Indian J Public Health Res Dev. 2015; 6: 118-22.

Singh M, Meena R, Saini GL. Epidemiological profile of influenza A $\mathrm{H} 1 \mathrm{~N} 1$ cases in Western Rajasthan in year 2013. Paripex Indian J Res. 2013; 2: 2646.

Singhal S, Sarda N, Arora R, Punia N, Jain A. Clinical profile \& outcome of H1N1 infected pregnant women in a tertiary care teaching hospital of Northern India. Indian J Med Res. 2014; 139: 4548.

Taklikar $\mathrm{C}$, and Nanaware $\mathrm{M}$. Epidemiological characteristics of $\mathrm{H} 1 \mathrm{~N} 1$ positive deaths: a study from tertiary care hospital in Western India. Int $\mathbf{J}$ Med Sci Public Health. 2013; 2: 305-8.

\section{How to cite this article:}

Thilakavathi, N., and Shanthi B. Rosyvennila. 2018. An Experience of Pandemic Influenza A (H1N1) 2009 Virus Outbreak in 2017 at Tertiary Care Hospital, Chennai, Tamilnadu, India. Int.J.Curr.Microbiol.App.Sci. 7(04): 3579-3584. doi: https://doi.org/10.20546/ijcmas.2018.704.403 